\title{
Research on the Improvement of Sino-Vietnamese Cooperation Mechanism
}

\author{
Di Wu \\ Kunming University of Science and Technology Oxbridge College, Kunming, Yunnan Province, China
}

Keywords: Sino-Vietnamese cooperation; problems; improvement.

\begin{abstract}
After a long period of cooperation and development, China and Vietnam have entered a relatively mature stage. The problems in the process of cooperation also show obvious features with the frequent exchanges between the two countries. Failures to deal with it or negative response cannot eliminate the difficulties of Sino-Vietnamese cooperation. From the perspective of benefit sharing between China and Vietnam, it is extremely important to seek a more reasonable mechanism in the process of cooperation and to improve it.
\end{abstract}

\section{Introduction}

In recent years, the political, economic and cultural exchanges between China and Vietnam have become more frequent. Eliminating mutual disputes only in the process of exchanges and consultations cannot fundamentally solve the problems between the two countries. And the existing dispute settlement mechanisms, for instance, the WTO, etc. still have deficiencies. Establishing a relatively complete cooperation mechanism can effectively resolve disputes and contradictions between China and Vietnam and provide favorable support for the development of bilateral relations. The essence of friction in the process of cooperation between China and Vietnam is the product of interest competition, which is unavoidable. This also shows that to some extent the frictions in the cooperation between China and Vietnam are multiple and intractable. In the case of unavoidable friction, if we simply pursue the interests or the authority of the country, it will inevitably produce serious consequences. The existing frictions are not uncontrollable. Establishing a relatively perfect cooperation mechanism and rationally distributing benefits under the premise of fairness is the result of bilateral expectations and a good way to achieve a win-win situation.

\section{Difficulties in the Choice of Sino-Vietnamese Cooperation Mechanism}

\subsection{Prevention and balances in historical imprints}

In January 2015, the $65^{\text {th }}$ anniversary of the establishment of diplomatic relations between China and Vietnam, the Vietnamese ambassador to China held a press conference in the Vietnamese Embassy in China and pointed out at the meeting that Vietnam is committed to establishing a peaceful, stable and friendly bilateral political relationship between China and Vietnam. In April 2015, President Jin-ping Xi met with the General Secretary of the Communist Party of Vietnam, Fu-zhong $\mathrm{Fu}$, at the Great Hall of the People, which made China and Vietnam more closely linked. Although China and Vietnam have established diplomatic relations for many years, the relations between the two countries are relatively close, in the long history, the two countries have experienced relatively tense political relations.

The connection between China and Southeast Asian countries can be traced back to a long history. In the process, it is inevitable to leave a mark. However, in the pessimistic scholars' perception, Southeast Asian countries, including Vietnam, deny that China has made contributions to them. But they are grateful to the short-lived peace that the Anglo-American colonists gave to them. This pessimistic argument is certainly not desirable, but it reflects that the historical problems between China and Vietnam will be an invisible barrier between the two countries.

During the $19^{\text {th }}$ and $20^{\text {th }}$ centuries, China has declined while Britain, the United States and Japan 
and some other imperialist countries successively encroached on China's interests. As a colony adjacent to China, Vietnam naturally inherited the interests of Chinese territories plundered by the colonists in this process. The most practical choice made in the face of reality has made Sino-Vietnamese relations rigid. [The rapid development of trade between Yunnan and Vietnam is promising. The Public of the People's Government of Yunnan Province, www.yn.gov.cn] In the early 1990s, China was committed to economic development and resumed diplomatic relations with Vietnam. However, the scars in the historical imprint will not disappear. When Vietnam invaded Cambodia, Thailand changed its policy toward China and formed an alliance with Vietnam to form some balance. The territorial issue is a top priority for all countries. The same state system will not weaken the sovereignty of countries over the territory. The border between China and Vietnam and the sovereignty disputes in Nansha have always existed. China and Vietnam have invisibly established their own precautions.

\subsection{Obvious competition and uneven interest distribution}

Vietnam has convenient geographical resources and abundant resources. It has its own advantages in cooperation with China. Vietnam joined ASEAN in 1995. With the rise of international status, it began to actively promote regional economic cooperation, including the cooperation with China named "two economic corridors and one economic circle". But Thailand's economic strength is strong and it has an unassailable position in Southeast Asian countries. The active operation of Vietnam has made Thailand feel the pressure. The proposal of Vietnam's major cooperation initiatives has triggered competition between Thailand and Vietnam. The formation of this competitive relationship provides conditions for the intervention of external forces and Sino-Vietnamese cooperation is relatively hindered.

At the same time, there is also a competitive force within China. Due to the restrictions of the Lancang-Mekong River, Yunnan Province cannot bear the burden of materials and personnel in Yunnan and Southeast Asia. The opening of the Nankun Railway further constrains the connection between Yunnan and Southeast Asian countries. The focus of GMS cooperation may tend to Guangxi. The competition between Yunnan and Guangxi also brought a series of problems for Sino-Vietnamese cooperation.

\subsection{Influences of great countries}

As a world superpower, the United States will have a major impact if it is strongly involved in the development process of other countries. [Cong-de Liu. Introduction to Geopolitics. Beijing: China Renmin University Press, 2010: 7.] In 2009, in the dialogue conference between the United States and ASEAN, the United States mentioned that the selection of ASEAN development strategic partners should exclude China from the Mekong River Basin. Subsequently, the United States intervened in the cooperation and development of the Mekong sub-region. This inevitably has an adverse impact on the development of cooperation between China and Southeast Asian countries including Vietnam.

Japan is a major contributor to the Mekong region. The dispute between Japan and China has existed since then and will continue to exist for a long time. Japan's China policy is largely committed to weaken China's strength. China and Vietnam have been controversial on the South China Sea issue. Japan's continued assistance to Vietnam must be trusted by Vietnam. Japan exploits Vietnam as a South China Sea issue has hampered China's power and will affect the development of cooperation between China and Vietnam.

Due to its geographical advantages, India's religion and culture have always affected other Southeast Asian countries, including Vietnam. At the same time, India actively participates in the Mekong River Basin development plan, builds the Indo-Burma Highway and considers the construction of a railway connecting India's New Delhi with Hanoi, Vietnam. Most of these plans in India are excluded from China. It shows that India has contained China's intention to develop in Southeast Asia. On the other hand, the cooperation between India and Vietnam in military relations has revealed unconcealed intentions to balance China. And the "Four National Democratic Alliance" 
of the United States, Japan, India and Australia reached a policy coordination against China and jointly hindered China's development in Southeast Asia, which shows that India's involvement also affects the links and cooperation between China and other Southeast Asian countries.

\section{The Improvement of Sino-Vietnamese Cooperation Mechanism and Its Prospects}

\subsection{Expansion and deepening of cooperation}

Sino-Vietnamese cooperation has a long history and achieved great results in cooperation in the fields of economy, trade, transportation, energy, tourism and environmental protection. However, if the cooperation between the two countries stays in the conventional field, it does not have the prospect of long-term development. The cooperation between China and Vietnam should be deepened on the original basis. For example, the Sino-Vietnamese transportation cooperation relationship is well developed and the achievements are remarkable. If the traffic construction can be strengthened and other roads other than the Mankun Highway and the Pan-Asia Railway are established, it will definitely lay the foundation for future development. China-Thailand high-speed rail has been included in the plan. If the construction of high-speed rail is put on the agenda in the Sino-Vietnamese cooperation, the transportation system of the Sino-Vietnamese road will be improved. At the same time, the waterway construction between Yunnan and Guangxi and Vietnam will be strengthened and the logistics platform such as the electronic port will be also developed. The development of various fields such as economy and tourism has more powerful support.

[Ya-qing Qin \& Ling Wei. Socialization of Structure, Process and Power [J]. World Economics and Politics, 2007 (3): 10.] The field has also been expanded accordingly. The development of other cooperation contents including health and epidemic prevention, drug control and talent development will help China and Vietnam maintain long-term cooperation and progress together. China and Vietnam are adjacent. The frequent personnel movements and loopholes in the control of the border between the two countries provide convenience for the spread of the epidemic and the circulation of drugs. Both China and Vietnam should pay attention to the important impact of safety while striving for economic development. At the same time, China-Vietnam economic differences are large. To achieve a win-win situation, China's provision of talent and technical support for Vietnam is also an indispensable force in ensuring the rapid development of its economy.

In addition to service and trade cooperation in tourism and transportation, there are other needs for service trade cooperation between China and Vietnam. In recent years, relatively good cooperation results have been achieved. But the current results are not the reason we stop.

Firstly, in terms of construction, Vietnam's own construction level is not high and the construction talents are limited. But its domestic economic development is good and its cities are growing fast and the construction market is huge. In addition to conventional buildings such as buildings, highways, and airports, Vietnam has a greater demand for planned buildings such as dams and power stations, which will be an important manifestation of Sino-Vietnamese construction cooperation in the future.

Secondly, in terms of finance, China and Vietnam have carried out currency settlement business in recent years and strengthened the cooperation of commercial financial institutions, which has facilitated the economic and trade cooperation between the two countries. With the development of regional economy and the promotion of integration, the financial cooperation between China and Vietnam will further weaken the commercial barriers in terms of investment and market access and deepen the bilateral cooperation and development.

Thirdly, in terms of education, the cultural exchanges between China and Vietnam have a long history and have achieved good development in education output and input. In order to promote further cooperation, the two countries will need to increase cooperation in the introduction and export of talents and technologies in the future, which will contribute to the bilateral win-win situation. 


\subsection{Enhancement of the strategic position of the economic cooperation in the Minjiang-Mekong sub-region}

The China-ASEAN sub-regional economic cooperation has had tremendous impact on the economic and trade relations between the two sides. The importance of sub-regional cooperation is self-evident. Although the Minjiang-Mekong sub-region is a part of the GMS and GMS is another economic system which is independent of the WTO and the China-ASEAN Free Trade Area, the success of other systems can still serve as the guiding force for the development of China and Vietnam.

Firstly, the strategy of China's western development provides guarantee for the promotion of the strategic position of sub-regional economic cooperation. [China-ASEAN Business Council Chinese Secretariat: China-ASEAN Economic and Trade Cooperation Report (2010-2011).] Yunnan and Guangxi, which are located in the southwest of China, have important positions for the development of the western region. This policy has led China to deepen its ties with the international community on a larger scale and at a deeper level. On this basis, China-Vietnam development has certain policy support.

Secondly, the sustainable development strategy strengthens the regional cooperation. [ Zhi Chen. Thoughts on Constructing the Dispute Settlement Mechanism of the Greater Mekong River Sub-region-Taking the Model of Regional Trade Dispute Settlement Mechanism as a Lesson. Around Sourtheast Aisa, 2008 (9). Jia Wei. Legal Thinking on the Dispute Settlement Mechanism of Pan-Beibu Gulf Economic Cooperation. The Border Economy and Culture, 2009 (7).] China's economic development started late but developed fast. This phenomenon is inevitably based on neglecting the environment. Southeast Asian countries, including Vietnam, which are dominant in agriculture and tourism, believe that China's development is not sustainable and the long-term nature of sub-regional economic cooperation has been questioned, leading to its neglect of its strategic position. Seeking the development path of economic and environmental coexistence as soon as possible is the top priority of China. The implementation of the sustainable development strategy and the practice over the years have dispelled the doubts of Southeast Asian countries on China's sustainable development and strengthened the sub-regional economic cooperation of all parties.

Thirdly, the adverse effects of the United States, Japan and other big countries on China-Vietnam development are based on the premise that the two countries are mutual suspicion and mutual balances. China and Vietnam attach importance to the important position of sub-regional economic cooperation. Under the situation of mutual benefit, big powers are involved. The influence will not be as good as before.

\subsection{Balanced distribution of interests to achieve a sharing mechanism}

Enhancing the strategic position of sub-regional economic cooperation has deepened the relationship between China and Southeast Asian countries, but the interests are important goals pursued by all countries. When conflicts of interests arise, there is nothing to do with the improved policy support. This also causes negative effects on Sino-Vietnamese cooperation.

[ Zong-ze Ruan. China's Rise and Mobilization of the Transformation of the International Order: The Shaping and Expansion of Shared Interests. Beijing: Peking University Press, 2007: 108.] Achieving the development of cooperation is necessary to break through the negative impact of narrow profit concept on the cooperation partners to form a common interest and achieve benefit sharing in order to promote the development and cooperation between the country and other countries in a more comprehensive and in-depth manner. For example, Yunnan and Guangxi in China should have the concept of overall nation. They should understand and cooperate with each other in cooperation with Southeast Asian countries including Vietnam and should not form hostile relations.

In the Sino-Vietnamese cooperation, the involvement of other Southeast Asian countries has caused Vietnam to form a competitive relationship with other countries, resulting in the phenomenon of robbing interests. The existence of the economic cooperation relationship between the Minjiang and Mekong sub-regions makes the alliance between China and Southeast Asian countries 
self-evident. In the contradiction between competition and cooperation, there must be trade-offs, re-cooperation and retention of competition, mutual support in the acquisition of relative interests and the sharing of benefits. It also provides an internal driving force for the development of the Minjiang-Mekong sub-region, further promoting the improvement of the Sino-Vietnamese cooperation mechanism.

\section{References}

[1] Edited by Xiao-song Gu. Strategic Conception of China-ASEAN Transportation Cooperation: Building Guangxi Sea, Land and Air Transportation Hub. Beijing: Social Sciences Academic Press (China), 2010: 10.

[2] Natural Resources and Economic Advantages of All Provinces, Municipalities and Autonomous Regions. China Society of Territorial Economists: 271, 311, 304.

[3] Wan-nan Li. Northern Growth Triangle: A Beneficial Attempt of ASEAN Sub-regional Economic Cooperation. China-ASEAN Panorama, 2007 (10).

[4] Cong-de Liu. Introduction to Geopolitics. Beijing: China Renmin University Press, 2010: 7.

[5] Ya-qing Qin \& Ling Wei. Socialization of Structure, Process and Power [J]. World Economics and Politics, 2007 (3): 10.

[6] China-ASEAN Business Council Chinese Secretariat: China-ASEAN Economic and Trade Cooperation Report (2010-2011). 